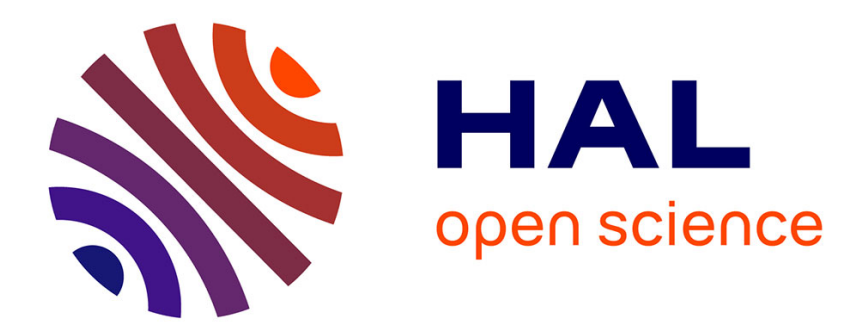

\title{
Adaptations of the Oxford Tables to Paris, Mantua, and Louvain
}

\author{
José Chabás, Bernard R Goldstein
}

\section{To cite this version:}

José Chabás, Bernard R Goldstein. Adaptations of the Oxford Tables to Paris, Mantua, and Louvain. Journal for the History of Astronomy, 2018, 49 (1), pp.99-115. 10.1177/0021828617752698 . hal02552956

\section{HAL Id: hal-02552956 \\ https://hal.science/hal-02552956}

Submitted on 23 Apr 2020

HAL is a multi-disciplinary open access archive for the deposit and dissemination of scientific research documents, whether they are published or not. The documents may come from teaching and research institutions in France or abroad, or from public or private research centers.
L'archive ouverte pluridisciplinaire HAL, est destinée au dépôt et à la diffusion de documents scientifiques de niveau recherche, publiés ou non, émanant des établissements d'enseignement et de recherche français ou étrangers, des laboratoires publics ou privés. 


\title{
Adaptations of the Oxford Tables to Paris, Mantua, and Louvain*
}

\author{
José Chabás \\ Universitat Pompeu Fabra, Barcelona, Spain
}

Bernard R. Goldstein

University of Pittsburgh, USA

\begin{abstract}
The Oxford Tables of 1348, also called Tabule anglicane, were computed for the meridian of Oxford in the framework of Alfonsine astronomy. They had a remarkable success, for they are extant in a good number of Latin manuscripts, and they were adapted repeatedly. This paper focuses on these adaptations: the Tabule Parisiensis, with radices for the year 1368 complete and the meridian of Paris, extant in Hebrew and Latin manuscripts; the version made by Mordecai Finzi, with radices for 1443 complete and the meridian of Mantua, preserved in a unique Hebrew manuscript; and the partial adaptation by Henry Baers printed in Latin in Louvain in 1528.
\end{abstract}

\section{Keywords}

Alfonsine Tables, Oxford Tables of 1348, Tabule Parisiensis, Mordecai Finzi, Henry Baers.

Introduction

The Oxford Tables, known at the time as Tabule anglicane, are a set of astronomical tables compiled for the meridian of Oxford by William Batecombe, with radices for 1348 following the Parisian Alfonsine Tables. ${ }^{1}$ This set is normally accompanied by a short text on its use, beginning Vera loca omnium planetarum in longitudine ac latitudine..., and consists of at least five different groups of tables: (i) mean motion tables, presented in anni collecti and anni expansi (with a period of 20 years), single years from 1 to 20, months, days, and hours, following the format in John of Lignères's Tables for 1322 and in his Tabule magne $(\mathrm{ca} .1325)^{2}$ and the period of 20 years found in the Toledan Tables and many others previous sets; (ii) a table for the true longitude of the Sun in a year, as a function of its mean longitude, following the presentation displayed by John Vimond, another early Alfonsine astronomer, ca. $1320 ;{ }^{3}$ (iii) a double argument table for the true longitude of the Moon, where the entries represent the true elongation between the two luminaries, as a function of mean lunar anomaly and mean elongation, similar in structure to that in John of Lignères's Tabule magne, but with different entries; (iv) five double argument tables for the true longitudes, one for each planet, as a function of their respective mean anomaly and mean center, which clearly depend

\footnotetext{
* This research has been undertaken in the frame work of ALFA, a European Research Council project (Consolidator grant 2016 agreement no. 723085) funded for 2017-2022.

${ }^{1}$ See J. D. North, "The Alfonsine Tables in England", in Y. Maeyama and W. G. Saltzer (eds.), Prismata: Festschrift für Willy Hartner (Wiesbaden, 1977), pp. 269-301. Reprinted in J. D. North, The universal frame: historical essays in astronomy, natural philosophy, and scientific method (London, 1989), pp. 327-359.

2 E. Poulle, "John of Lignères", in Dictionary of Scientific Biography, 7, pp. 122-128 (New York, 1973).

${ }^{3}$ J. Chabás and B. R. Goldstein, "Early Alfonsine Astronomy in Paris: The Tables of John Vimond (1320)", Suhayl, 4, 2004, pp. 207-294.
} 
on those in the Tabule magne; and (v) five double argument tables, one for each planet, again as a function of their respective mean anomaly and mean center, which have no counterpart in other similar previous sets of tables. All tables strictly adhere to Alfonsine astronomy, which was recast in the 1320s in Paris based on the non-extant tables produced by the astronomers in the service of Alfonso X, King of Castile and León, in the 1270s, and share all its geometrical models and numerical parameters. ${ }^{4}$ However, in contrast to the Parisian Alfonsine Tables which use signs of $60^{\circ},{ }^{5}$ these tables all use zodiacal signs of $30^{\circ}$.

\section{The Oxford Tables in Paris}

The Oxford Tables were disseminated widely throughout Europe and, in particular, the double argument tables for the planets are preserved, often isolated from the rest of the set, in a few dozen manuscripts. Presumably, the main reasons for their success are that these compact double argument tables give directly quantities that in previous sets had to be computed appealing to various tables; they depend neither on the geographical location of the observer nor on a specific date, and are thus both user-friendly and universal. These characteristics may explain why several astronomers adapted the rest of the Oxford Tables to other meridians. This is the case of the anonymous Tabule Parisiensis, recompiled for the meridian of Paris and with radices for 1368. It is immediately seen that the difference between the radices of the two sets mentioned so far is 20 years, exactly the same period used in the mean motion tables for Oxford. Thus, for the adaptation of the new set the author had only to take care of the difference in longitude between Oxford and Paris, 5;4 or 0;20,16h, a value, by the way, that had been used 20 years earlier for compiling the Oxford Tables from the tables set up for Paris. ${ }^{6}$ In this sense, the Tabule Parisiensis provide an infrequent example of back and forth transmission between two main centers of astronomical activity, Paris and Oxford.

The Tabule Parisiensis are associated with two different texts in Latin. One has the incipit, Cum astrologis solis inter omnis philosophos..., and we have found it in two manuscripts, both also containing the tables: Cambridge, Gonville and Caius College, MS 110/179, 101-191 (tables), 192 195 (canons), henceforth, MS Cl; and Vatican, Biblioteca Apostolica, MS Pal. lat. 1436, 37r-39r (canons), 42r-87r (tables), henceforth, MS Vl. ${ }^{7}$ In both manuscripts the canons have eight chapters in common, dealing with general characteristics of the tables such as the use of signs of $30^{\circ}$, the definition of the beginning of the day at noon of the previous day in the civil calendar, and the fact that the radices are set for 1368, complete (i.e., noon, Dec. 31, 1368), and are computed for the meridian of Paris. There follow explanations of the true positions of the Sun, the Moon, and the planets, as well as of the revolution of the years and the 8th sphere, thus indicating the use of tropical coordinates, as in the Oxford Tables and elsewhere in Alfonsine astronomy. The chapter on the motion of the 8th sphere provides some specific data: (1) the motion between Ptolemy's and Alfonso's time is $17 ; 8^{\circ},{ }^{8}(2)$ the motion from Alfonso's time to the end of 1368 it is $1 ; 22,18,43^{\circ}$, and

\footnotetext{
${ }^{4}$ J. Chabás and B. R. Goldstein, The Alfonsine Tables of Toledo. Archimedes: New Studies in the History and Philosophy of Science and Technology, 8 (Dordrecht and Boston, 2003).

${ }^{5}$ E. Ratdolt (ed.), Tabule astronomice illustrissimi Alfontij regis castelle (Venice, 1483).

${ }^{6}$ For these values in the Oxford Tables, see for example, Vatican, Biblioteca Apostolica, MS Pal. lat. 1376, 381rb, lines 5-9.

${ }^{7}$ As the canons and tables of the Tabule Parisiensis are extant both in Latin and in Hebrew, we have added an "l" or an "h", respectively, to the sigla assigned to the manuscripts. A description of $\mathrm{Cl}$ (later half of the 14th c.) can be found in Pedersen 2002, pp. 96-97. For a description of V1 (mid 15th c., composed in what is now Belgium), see Schuba 1992, pp. 224-226; a copy online is accesible at: http://digi.ub.uni-heidelberg.de/diglit/bav_pal_lat_1436? ui_lang=ger.

${ }^{8}$ On the value $17 ; 8^{\circ}$ for precession from the time of Ptolemy to the time of King Alfonso X see, e.g., J. Chabás and B. R. Goldstein, A Survey of European Astronomical Tables in the Late Middle Ages (Leiden and Boston,
} 
(3) correctly gives the sum of these two quantities, $18 ; 30,18,43^{\circ} .{ }^{9}$ The common text ends with Et isti canones tibi sufficiant ad presens. However, manuscript $\mathrm{Vl}$ has eight additional chapters, concerning retrogradation, the lunar nodes, the length of the day, and the latitude of regions, among other topics. In manuscript $\mathrm{Cl}$, the canons are followed by a text (ff. 196-197), beginning Ad intelligendum tabulas astronomiae necessario oportet scire..., consisting of a series of definitions and short explanations of astronomical concepts such as radix, solar apogee, retrogradation, ascending node, solar year, etc., reminiscent of the contents of the eight additional chapters in MS Vl.

The other text begins Ad habendum noticiam et introitum in tabulis Parisiensibus..., and it is extant in Dijon, Bibliothèque municipale, MS 447, 63r-70v, and Paris, Bibliothèque nationale de France, MS 7287, 87r-91r. ${ }^{10}$ There are no tables associated with either of them. This text differs substantially from the preceding one; it is divided into nine chapters that explain the use of the tables and indicate that they were composed for the meridian of Paris, with radices set for year 1368, complete. In the chapter on the motion of the 8th sphere, there is a worked example for October 20, 1443, complete. The canons in the manuscript in Paris are followed by the same text with definitions of astronomical concepts (ff. 91r-92r), beginning Ad intelligendum tabulas astronomiae necessario oportet scire..., as was the case in MS Cl. The same text is found in yet another manuscript, Paris, Bibliothèque nationale de France, MS 7295A, 99r-v and 114r, where it is not associated with the Tabule Parisiensis.

This set of tables for Paris is also found in a Hebrew version, based on the Latin, but the canons in the Hebrew manuscripts differ from each other as well as from their counterparts in Latin. As we shall see, there are also differences between the Hebrew and Latin versions concerning the radices for 1368. The three Hebrew copies of the Tabule Parisiensis are: Munich, Bayerische Staatsbibliothek, MS Heb. 343, 104b-107a (canons), 154a (canons to the latitude tables), 108a-166a (tables), henceforth MS Mh; Oxford, Bodleian Library, MS Reggio 14, 57a-93a (tables), 57a-60a in the margins only (canons), henceforth MS Oh; Parma, Biblioteca Palatina, MS 2112, 35a (canons to the latitude tables), 35b-48a (latitude tables only), henceforth MS Ph. Note that MS Ph has no information on radices, apogees, or longitudes. In Mh 104b, 154a, and $\mathrm{Ph} 35 \mathrm{a}$ the name of the translator is given as Solomon ben Davin of Rodez (ca. 1370, (southern France); but no author or translator is named in MS Oh. ${ }^{11}$

2012), p. 185. MS V1 has a variant reading of 17;28 . See also M. Comes, "Al-Șūfĩ como fuente del libro de la 'Ochava Espera' de Alfonso X", in "Ochava espera” "y "astrofisica”: textos y estudios sobre las fuentes árabes de la astronomía de Alfonso X, ed. by M. Comes, H. Mielgo, and J. Samsó (Barcelona, 1990), 11-113, especially p. 16.

${ }^{9} \mathrm{Mh}, 105 \mathrm{~b}$, has the same information, with the variant $1 ; 23,18,43^{\circ}$ instead of $1 ; 22,18,43^{\circ}$. Oh, 59a-b, agrees with the Latin except for the sum, which is given as $25 ; 10,18,43^{\circ}$. We have not succeeded in recomputing the difference given for the motion of the 8th sphere from Alfonso's time to the end of $1368\left(18 ; 28,46^{\circ}\right)$. We have considered the epoch of Alfonso to be December 31, 1251, in which case we obtain $18 ; 28,46^{\circ}-17 ; 14,28^{\circ}=$ $1 ; 14,18^{\circ}$. Taking the time of Alfonso to mean May 31, 1252 (the date of his accession to the throne), the result is $18 ; 28,46^{\circ}-17 ; 14,45^{\circ}=1 ; 14,1^{\circ}$. Both values are far from that given in the text.

${ }^{10}$ On this 15 th century manuscript kept in Paris, see J.-P. Boudet, Lire dans le ciel (Bruxelles, 1994), pp. 2635. The scribe of the manuscript is a certain Martinus, working "in Cabeolo" (see item 14). This place, hitherto unidentified, could be Chabenil or Chabeuil (Drôme), in the vicinity of Valence, France, as indicated in the online version of the Dictionnaire topographique du Département de la Drôme: Districte de Valence, Paris, 1891: http://cths.fr/dico-topo/dictionnaires/fichiers/DT26IntroductionAnnexes.pdf.

${ }^{11}$ On Solomon ben Davin, a disciple of Immanuel Bonfils (ca. 1350, Tarascon), see M. Steinschneider, Mathematik bei den Juden, 2nd ed. (Hildesheim, 1964), p. 166, and E. Renan and A. Neubauer, Les écrivains juifs français du XIV siècle (Paris, 1893), pp. 763-766. In MS Mh, 104b, the canons begin: "Solomon ben Davin of Rodez, student, said..."; this is sometimes abbreviated to the initials in Hebrew AŠDT [= Amar Šelomo Davin Talmid]. The term "student" (here used as a term expressing humility) also occurs after the name of Moses Farissol Botarel, where the initials are NFT [= Ne'um Farissol Talmid]. On Farisol Botarel, an 
Moreover, not all five manuscripts contain full versions of this set of tables, notably MS Cl lacks some tables corresponding to the true positions of the planets and MSS Mh and Ph are the only ones with tables for planetary latitudes.

1. Radices and mean motions: $\mathrm{Cl}, 101-107$; Vl, 42r-45r; Mh, 108a-112a; Oh, 57a-60b.

There are 4 subtables for the mean motions. The first displays the radices for 1368 complete (noon of the last day in December) and the mean motions for each year from $1 \mathrm{y}$ to $20 \mathrm{y}$, then for every $20 \mathrm{y}$ to $100 \mathrm{y}$, for every $100 \mathrm{y}$ to $1000 \mathrm{y}$, and finally for $2000 \mathrm{y}$, for each quantity indicated in Tables 1 and 2. The three other subtables provide entries for the months in a year, the days in a month, and the hours in a day for each quantity.

Table 1: Radices for 1368 complete and mean motions in a year in the Latin MSS

\begin{tabular}{|c|c|c|}
\hline & Radix & Mean motion in $1 \mathrm{y}$ \\
\hline Revolution (motion) & $176 ; 34,0^{\circ}$ & $87 ; 19,6^{\circ}$ \\
\hline Revolution (time) & $5 ; 46,16 h^{*}$ & $5 ; 49 ; 16 h$ \\
\hline Mean solar argument & 6s $18 ; 38,58,44^{\circ} *$ & 11 s $29 ; 45,39,22^{\circ}$ \\
\hline Mean elongation & 8 s $17 ; 41,49,56^{\circ *}$ & $4 \mathrm{~s} \quad 9 ; 37,23,15^{\circ}$ \\
\hline Mean lunar anomaly & 1s $6 ; 49,44,12^{\circ *}$ & 2s $28 ; 43,14,50^{\circ *}$ \\
\hline Ascending node & $9 \mathrm{~s} 1 ; 2,0^{\circ} *$ & 0s $19 ; 21,55^{\circ *}$ \\
\hline Saturn, mean center & $11 \mathrm{~s} 29 ; 12,34^{\circ}$ & $0 \mathrm{~s} 12 ; 13,35^{\circ}$ \\
\hline Saturn, mean anomaly & 1s $7 ; 14,6^{\text {oa }}$ & 11 s $17 ; 32,5^{\circ}$ \\
\hline Jupiter, mean center & $4 \mathrm{~s} 23 ; 55,26^{\circ}$ & 1s $\quad 0 ; 20,29^{\circ}$ \\
\hline Jupiter, mean anomaly & $11 \mathrm{~s} \quad 2 ; 17,56^{\mathrm{ob}}$ & 10s $29 ; 25,10^{\circ}$ \\
\hline Mars, mean center & $1 \mathrm{~s} 14 ; 19,39^{\circ}$ & $6 \mathrm{~s} 11 ; 17,6^{\circ}$ \\
\hline Mars, mean anomaly & $3 \mathrm{~s} 20 ; 8,30^{\circ}$ & 5s $18 ; 28,34^{\mathrm{oc}}$ \\
\hline Venus, mean center & $6 s 18 ; 24,58,44^{\text {od }}$ & 11 s $29 ; 45,39,22^{\circ}$ \\
\hline Venus, mean anomaly & $0 \mathrm{~s} 18 ; 50,5^{\circ}$ & $7 \mathrm{~s} 15 ; 1,42^{\circ}$ \\
\hline Mercury, mean center & 2s $19 ; 10,49^{\circ}$ & 11 s $29 ; 45,39^{\circ}$ \\
\hline Mercury, mean anomaly & 0s $26 ; 24,51^{\circ}$ & $1 \mathrm{~s} 23 ; 56,47^{\circ}$ \\
\hline Access and recess & 2s $9 ; 33,48^{\circ}$ & $0 \mathrm{~s} \quad 0 ; 3,5^{\circ}$ \\
\hline Apogees and fixed stars & $0 \mathrm{~s} 10 ; 3,2^{\circ}$ & os $0 ; 0,27^{\circ}$ \\
\hline
\end{tabular}

* Illegible in $\mathrm{Cl}$.

a. Vl: $1 \mathrm{~s} 7 ; 24,6^{\circ}$.

b. Vl: $11 \mathrm{~s} 2 ; 17,58^{\circ}$.

c. Vl: 5 s $18 ; 28,24^{\circ}$.

d. Vl: $6 \mathrm{~s} 18 ; 38,58,44^{\circ}$.

The entries for the mean elongation and the mean lunar anomaly in Table 1 agree exactly with recomputation with the Parisian Alfonsine Tables for Dec. 31, 1368, noon, Paris (= Dec. 30, 1368,$23 ; 12 \mathrm{~h}$ after noon, Toledo, for the difference between Paris and Toledo is $0 ; 48 \mathrm{~h}$ ). This means that the moment in time for the radices is secure. Nevertheless, the entry for the mean solar argument, $6 \mathrm{~s} 18 ; 38,58,44^{\circ}$, differs from the value recomputed with the Parisian Alfonsine Tables for 
that time, $6 \mathrm{~s} 18 ; 27,55^{\circ}$, that is, the difference is about $0 ; 11^{\circ}$, which corresponds to the solar motion in about $4 \frac{1}{2} \mathrm{~h}$. The entry for the mean center of Venus, $6 \mathrm{~s} 18 ; 24,58,44^{\circ}$, should be the same as that for the mean solar argument, but this is not the case here (the minutes differ, but the seconds and thirds agree).

Table 2 lists the radices in the two Hebrew manuscripts for noon, Dec. 31, 1368 for three different cities. The entries in the column headed "Horizon of Avignon" have been recomputed with the Parisian Alfonsine Tables for Dec. 30, 1368, 22;30h after noon, Toledo; those in the column headed "Horizon of Paris" have been recomputed with the Parisian Alfonsine Tables for Dec. 30, 1368,$23 ; 12 \mathrm{~h}$ after noon, Toledo, taking the difference in longitude between Toledo and Paris as $12^{\circ}$ or $0 ; 48 \mathrm{~h}$; and those in the column headed "Horizon of Lyon" have been recomputed with the Parisian Alfonsine Tables for Dec. 30, 1368, 22;52h after noon, Toledo. The columns for Avignon and Lyon have no counterparts in the Latin copies of the Tabule Parisiensis that we consulted. In the editio princeps of the Parisian Alfonsine Tables the longitudes of these three cities are the same, $22 ; 20^{\circ},{ }^{12}$ but here they differ. The time difference between Paris and Avignon of 0;42h corresponds to a difference in longitude of $10 ; 30^{\circ}$, and the time difference between Paris and Lyon of $0 ; 20 \mathrm{~h}$ corresponds to $5^{\circ}$. In fact, the longitudes of Avignon and Lyon are virtually identical and differ from that of Paris by about $2 \frac{1}{2^{\circ}}$. It has not been determined if these additional columns come from an undiscovered Latin version of these tables or if they were added in the Hebrew version.

Table 2: Radices in the two Hebrew MSS for 1368 complete.

\begin{tabular}{|c|c|c|c|c|}
\hline $\begin{array}{l}\text { Marginal notes } \\
\text { in Oh in Latin } \\
\text { (Hebrew script) }\end{array}$ & Mean Radices & $\begin{array}{l}\text { Horizon of } \\
\text { Avignon }\end{array}$ & $\begin{array}{l}\text { Horizon of } \\
\text { Paris }\end{array}$ & $\begin{array}{l}\text { Horizon of } \\
\text { Lyon }\end{array}$ \\
\hline $\begin{array}{l}\text { argumentum } \\
\text { solis }\end{array}$ & [Mean] solar argument & $6 \mathrm{~s} 18 ; 33,16^{\circ}$ & $6 s 18 ; 34,59^{\circ}$ & $6 s 18 ; 24,9^{\circ}$ \\
\hline \multirow[t]{2}{*}{$\begin{array}{l}\text { elongasionis } \\
\text { lune }\end{array}$} & $\begin{array}{l}\text { [Mean] elongation of } \\
\text { the Moon }\end{array}$ & 8 s $17 ; 20,31^{a}$ & 8 s $17 ; 41,49$ & 8s $17 ; 31,40$ \\
\hline & [Mean] lunar anomaly & 1s $6 ; 26,0$ & 1s $6 ; 49,44$ & 1s $6 ; 38,51$ \\
\hline caput draconis & Ascending node & 9s $1 ; 18,53$ & 9s $1 ; 19,0$ & $\begin{array}{ll}\mathrm{s} & 1 ; 19,40\end{array}$ \\
\hline centri & Saturn, [mean] center & $11 \mathrm{~s} 29 ; 12,30$ & $11 \mathrm{~s} 29 ; 12,34$ & 11s $29 ; 12,32$ \\
\hline $\begin{array}{l}\text { argumentum } \\
\text { saturni }\end{array}$ & Saturn, [mean] anomaly & 1s $7 ; 12,26$ & 1s $7 ; 14,6$ & 1s $7 ; 13,19$ \\
\hline \multirow[t]{2}{*}{ centri jovis } & Jupiter, [mean] center & 4 s $23 ; 55,17$ & 4 s $23 ; 55,26$ & $4 \mathrm{~s} 23 ; 55,22^{\mathrm{b}}$ \\
\hline & Jupiter, [mean] anomaly & $11 \mathrm{~s} \quad 2 ; 16,26$ & $11 \mathrm{~s} \quad 2 ; 17,56$ & $11 \mathrm{~s} \quad 2 ; 17,10$ \\
\hline \multirow[t]{2}{*}{ martis } & Mars, [mean] center & 1s $14 ; 18,44$ & 1s $14 ; 19,39$ & 1s $14 ; 19,13$ \\
\hline & Mars, [mean] anomaly & 3 s $20 ; 7,42$ & 3 s $20 ; 8,30$ & 3 s $20 ; 8,7$ \\
\hline \multirow[t]{2}{*}{ venuris } & Venus, [mean] center & $6 \mathrm{~s} 18 ; 23,11^{\mathrm{c}}$ & $6 \mathrm{~s} 18 ; 24,59^{\mathrm{d}}$ & $6 s 18 ; 24,9^{\mathrm{e}}$ \\
\hline & Venus, [mean] anomaly & 0s $18 ; 49,1$ & 0 s $18 ; 20,5$ & 0s $18 ; 29,34$ \\
\hline \multirow[t]{2}{*}{ mercurii } & Mercury, [mean] center & 2s $19 ; 9,2$ & 2s $19 ; 10,49$ & 2s $19 ; 16,29^{f}$ \\
\hline & $\begin{array}{l}\text { Mercury, [mean] } \\
\text { anomaly }\end{array}$ & 0s 26;19,25 & 0s $26 ; 24,51$ & 0 s $26 ; 22,16$ \\
\hline $\begin{array}{l}\text { motus equesus } \\
\text { [equationis] }\end{array}$ & $\begin{array}{l}\text { Motion of the 8th } \\
\text { sphere }\end{array}$ & $2 \mathrm{~s} \quad 9 ; 33,48$ & $2 \mathrm{~s} \quad 9 ; 33,48$ & 2s $9 ; 33,48$ \\
\hline equasionis & and its correction & 0s $\quad 8 ; 28,41$ & 0s $8 ; 28,44^{g}$ & 0s $8 ; 28,44^{\mathrm{h}}$ \\
\hline \multirow[t]{2}{*}{$\begin{array}{l}\text { vetus abogeum } \\
\text { [apogeum] }\end{array}$} & $\begin{array}{l}\text { Motion of the apogees } \\
\text { and the fixed stars }\end{array}$ & 0 s $10 ; 3,2$ & 0 s $10 ; 3,2^{\mathrm{i}}$ & 0s $10 ; 3,2^{j}$ \\
\hline & $\begin{array}{l}\text { Motion of the apogees } \\
\text { with their corrections }\end{array}$ & 0s $18 ; 31,42^{\mathrm{k}}$ & 0s $18 ; 31,42^{1}$ & 0s $18 ; 31,42^{\mathrm{m}}$ \\
\hline
\end{tabular}

${ }^{12}$ Ratdolt (Op. cit., n. 5), m5r. 

a. With Oh: 31; Mh: 38.
b. With Oh: 23; Mh: 24.
c. With Oh: 23; Mh: 33.
d. With Oh: 24; Mh: 34.
e. With Mh: 24; Oh: 54.
f. With Oh: 16; Mh: 56 .
g. With Mh; Oh blank.
h. With Mh; Oh blank.
i. With Mh; Oh mg: these four radices [for Paris and Lyon] are all equal [to the radices for Avignon].
j. With Mh; Oh blank, see note i.
k. With Mh; Oh: 8 .
1. With Mh; Oh blank, see note i.
m. With Mh; Oh blank, see note i.

Radices for the revolution, both in motion and in time, are given in the two Hebrew manuscripts (Mh, 108a, and $\mathrm{Oh}, 57 \mathrm{~b}$ ) as $176 ; 34,0^{\circ}$ and 5;46,16h, respectively, for Paris, and $176 ; 34,6^{\circ}$ and 5;46,9h, respectively, for Lyon. Those for Paris are in agreement with their counterparts in the Latin manuscripts with the following exceptions: mean solar argument, ascending node, Saturn (mean anomaly), Venus (mean center and mean anomaly). The entries in the row for the mean solar argument are textually secure, but seem to have been miscopied or miscomputed. In the column for Paris, the text has $6 \mathrm{~s} 18 ; 34,59^{\circ}$ but, as indicated above, recomputation with Parisian Alfonsine Table for Dec. 30, 1368, 23;12h after noon, Toledo, yields $6 s 18 ; 27,55^{\circ}$ (the difference of about $0 ; 7^{\circ}$ corresponds to the solar motion in about 3 hours). The entry for the mean center of Venus should be the same as that for the mean solar argument, but this is not the case here. However, the entry in the Hebrew MSS for the mean center of Venus agrees with the corresponding entry in the Latin MSS (see Table 1). This suggests that the entries for the mean center of Venus for all three horizons are to be preferred over the entries for the mean solar argument. Still, the recomputed values for these three entries, $6 \mathrm{~s} 18 ; 26,12^{\circ}$ (Avignon), $6 \mathrm{~s} 18 ; 27,55^{\circ}$ (Paris), and 6s 18;27,6 $6^{\circ}$ (Lyon), differ systematically from the entries in Table 2 by $0 ; 3^{\circ}$.

MS Vl, 45r, and MS Cl, 107, have a separate table with radices for Liège displaying values of the apogees of the Sun and the five planets. In Table 3 we present the apogees in the Latin and Hebrew MSS of the Tabule Parisiensis, as well as those in one manuscript of the Oxford Tables (Vienna, Österreichische Nationalbibliothek, MS 2440, 21r).

Table 3: Apogees

\begin{tabular}{|l|l|l|l|}
\hline Planet & Latin MSS & Hebrew MSS & Oxford Tables \\
\hline Sun and Venus & 2s $29 ; 57,5,42^{\circ}$ & 2s $29 ; 57,6^{\circ}$ & 2s $29 ; 41,51^{\circ}$ \\
\hline Saturn & 8s $11 ; 55,24,46$ & $8 \mathrm{~s} 11 ; 55,25$ & $8 \mathrm{~s} 11 ; 40,10$ \\
\hline Jupiter & 5s $22 ; 8,42,46$ & $5 \mathrm{~s} 21 ; 59,20^{\mathrm{a}}$ & $5 \mathrm{~s} 21 ; 53,28$ \\
\hline Mars & 4s $13 ; 43,55,46$ & 4s $13 ; 43,56$ & $4 \mathrm{~s} 13 ; 28,41$ \\
\hline Mercury & 6s $29 ; 11,15,46$ & 6s $29 ; 11,16$ & 6s $28 ; 56,1$ \\
\hline
\end{tabular}

a. With Oh; Mh: 5s 21;39,20.

Note that the values for the apogees in the Latin and Hebrew manuscripts agree, but for Jupiter, where there is a difference of $0 ; 9,23^{\circ}$. When comparing the values in the Oxford Tables with 
those in MS Vl, we find a difference of $0 ; 15,15^{\circ}$ in all cases. However, this is not true for Jupiter in the Hebrew manuscripts, indicating that the Hebrew tradition, as represented by manuscripts reported here, introduced a faulty value (or was based on a faulty Latin tradition).

2. Equation of the 8th sphere, lunar latitude, and solar declination: $\mathrm{Cl}, 108 ; \mathrm{Vl}, 45 \mathrm{v} ; \mathrm{Mh}, 112 \mathrm{~b}$; Oh, 61a.

These three tables are not found among the Oxford Tables, but are characteristic of Alfonsine astronomy. All have a maximum value for argument $90^{\circ}: 9 ; 0^{\circ}$ for the equation of the 8 th sphere, $5 ; 0^{\circ}$ for lunar latitude, and $23 ; 33^{\circ}$ for solar declination. In MS Vl, the equation of the 8 th sphere and the lunar latitude are found in the same table, as is the case of Mh and Oh.

3. Equation of center and first station: $\mathrm{Cl}, 109$; Vl, 46r; Mh, 113a; Oh, 61b.

This table is not found among the Oxford Tables. It is a single table for all planets, with a common double column for the argument, given at intervals of $6^{\circ}$ from $0 \mathrm{~s} 0^{\circ}$ to $6 \mathrm{~s} 0^{\circ}$, and their complement to 12s. For each planet two columns are displayed: one for the equation of center and another for the first station, both given in degrees and minutes (see Table 4). The values for the equation of center are strictly Alfonsine and those for the first station agree with those in the Toledan Tables.

Table 4: Equation of center and first station in MSS Cl, Vl, Mh, and Oh (excerpt)

\begin{tabular}{|c|c|c|c|c|c|c|c|c|c|c|c|}
\hline \multirow{2}{*}{\multicolumn{2}{|c|}{$\begin{array}{l}\text { Argument } \\
\left(\mathrm{s},{ }^{\circ}\right)\end{array}$}} & \multicolumn{2}{|c|}{ Saturn } & \multicolumn{2}{|c|}{ Jupiter } & \multicolumn{2}{|c|}{ Mars } & \multicolumn{2}{|c|}{ Venus } & \multicolumn{2}{|c|}{ Mercury } \\
\hline & & Equ. & Sta. & Equ. & Sta. & Equ. & Sta. & Equ. & Sta. & Equ. & Sta. \\
\hline $\begin{array}{ll}0 & 0\end{array}$ & 120 & $0 ; 0$ & $22 ; 44$ & $0 ; 1$ & $4 ; 5^{b}$ & $0 ; 0$ & $7 ; 28$ & $0 ; 0$ & $15 ; 51$ & $0 ; 0$ & $27 ; 14$ \\
\hline 06 & 1124 & $0 ; 40$ & $22 ; 45$ & $0 ; 36$ & $4 ; 5$ & $1 ; 5$ & $7 ; 33$ & $0 ; 13$ & $15 ; 53$ & $0 ; 17$ & 27,12 \\
\hline 012 & 1118 & $1 ; 17$ & $22 ; 47^{\text {a }}$ & $1 ; 11$ & $4 ; 6$ & $2 ; 10$ & $7 ; 38$ & $0 ; 26$ & $15 ; 54^{\mathrm{c}}$ & $0 ; 33$ & $27 ; 8$ \\
\hline 30 & 90 & $6 ; 31$ & $24 ; 11$ & $5 ; 57$ & $5 ; 42$ & $11 ; 23$ & $13 ; 25$ & $2 ; 10$ & $17 ; 11$ & $3 ; 1$ & $24 ; 37$ \\
\hline 36 & 824 & $6 ; 30$ & $24 ; 19$ & $5 ; 57$ & 5,50 & $11 ; 24$ & $13 ; 57$ & $2 ; 10$ & $17 ; 17$ & $3 ; 2$ & $24 ; 34$ \\
\hline$\cdots$ & & & & & & & & & & & \\
\hline 524 & 66 & $0 ; 43$ & $25 ; 28$ & $0 ; 39$ & $7 ; 11$ & $1 ; 20$ & $19 ; 11$ & $0 ; 14$ & $18 ; 20$ & $0 ; 19$ & $24 ; 41$ \\
\hline 60 & 60 & $0 ; 0$ & $25 ; 30$ & $0 ; 0$ & $7 ; 11$ & $0 ; 0$ & $19 ; 15$ & $0 ; 0$ & $18 ; 21$ & $0 ; 0$ & $24 ; 42$ \\
\hline
\end{tabular}
a. Mh and Oh: 22;46.
b. Vl: $4 ; 3$.
c. Vl: $15 ; 55$.

The entries for first station in Table 4 are displayed in degrees and minutes but the number of signs is not specified. In the Hebrew MSS the number of signs is given above and below the column for each planet, whereas in Vl, it is given just above the entries for $90^{\circ}$ and $180^{\circ}$ for each planet.

4. True solar position: $\mathrm{Cl}, 110-111 ; \mathrm{Vl}, 46 \mathrm{v}-47 \mathrm{r}$; Mh, 113b-114a; Oh, 62a-b. 
This table for the true longitude of the Sun is exactly the same, but for scribal errors, as the corresponding one in the Oxford Tables, and it is said to be valid for any place and any time, as indicated in the title in MS Vl, Tabula veri loci solis pro omni loco et tempore constituta, which, however, adds data incipiens ab anno Christi completo 1368. The argument is displayed for each integer degree beginning in Cancer and represents the mean solar longitude. The entries, in signs, degrees, and minutes are the true solar positions and result from adding the Alfonsine solar equation to the corresponding mean position: see Table 5. It is readily seen that the extreme entries are $+1 ; 52^{\circ}$ (at Psc $30^{\circ}$ ) and $-2 ; 28^{\circ}$ (at $\operatorname{Vir} 30^{\circ}$ ). The difference between these two values is $4 ; 20^{\circ}$, which is twice the value of the Alfonsine maximum solar equation, $2 ; 10^{\circ}$.

Table 5: True solar position (excerpt $)^{13}$

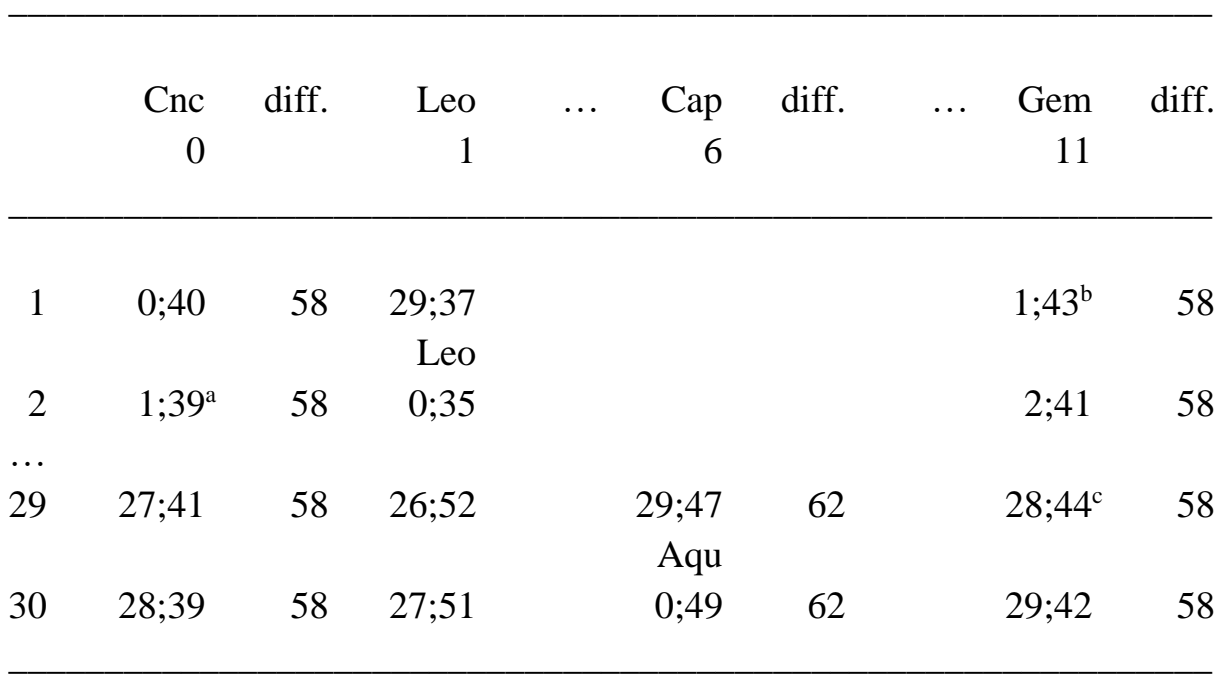

a. Mh and Oh: 1;38.

b. Mh and Oh: $1 ; 42$.

c. Cl: $28 ; 42$.

5. True longitude of the Moon: $\mathrm{Cl}, 112-125 ; \mathrm{Vl}, 47 \mathrm{v}-54 \mathrm{r}$; Mh, 114b-120a; Oh, 63a-68b.

As was the case for the table for the true longitude of the Sun, this table for the Moon is exactly the same, but for scribal errors, as the corresponding one in the Oxford Tables, and it is also valid for any place and any time. It is a double argument table, with mean lunar anomaly, $\alpha$-bar, displayed at intervals of $6^{\circ}$, at the head of the columns, and mean elongation, $\eta$-bar, at intervals of $3^{\circ}$, at the left side of the table (in the Hebrew manuscripts, on the right side). The entries are given in signs, degrees, and minutes, and represent the elongation between the mean Sun and the true Moon. We display selected columns and rows, in particular the last row, for a mean elongation of $6 \mathrm{~s} 0^{\circ}$ and $12 \mathrm{~s} 0^{\circ}$, contains entries which result from adding the mean lunar longitude to the equation of lunar anomaly: see Table 6 (transcribed from the Latin MSS with variants from the Hebrew MSS). It is readily seen that the extreme values of the equation of anomaly occur when mean lunar anomaly is $3 \mathrm{~s} 6^{\circ}$ and $8 \mathrm{~s} 24^{\circ}$, where the values for the equation of anomaly are, respectively, $-4 ; 56^{\circ}$ and $+4 ; 56^{\circ}$, which are indeed the characteristic parameters of Alfonsine astronomy. ${ }^{14}$

\footnotetext{
${ }^{13}$ In the Hebrew MSS the column headed "difference" is mostly blank.

${ }^{14}$ For a detailed analysis of this particular table, see J. Chabás and B. R. Goldstein, "The Moon in the Oxford Tables of 1348", Journal for the History of Astronomy, 47, 2016, pp. 159-167.
} 
Table 6: Elongation between the mean Sun and the true Moon (excerpt)

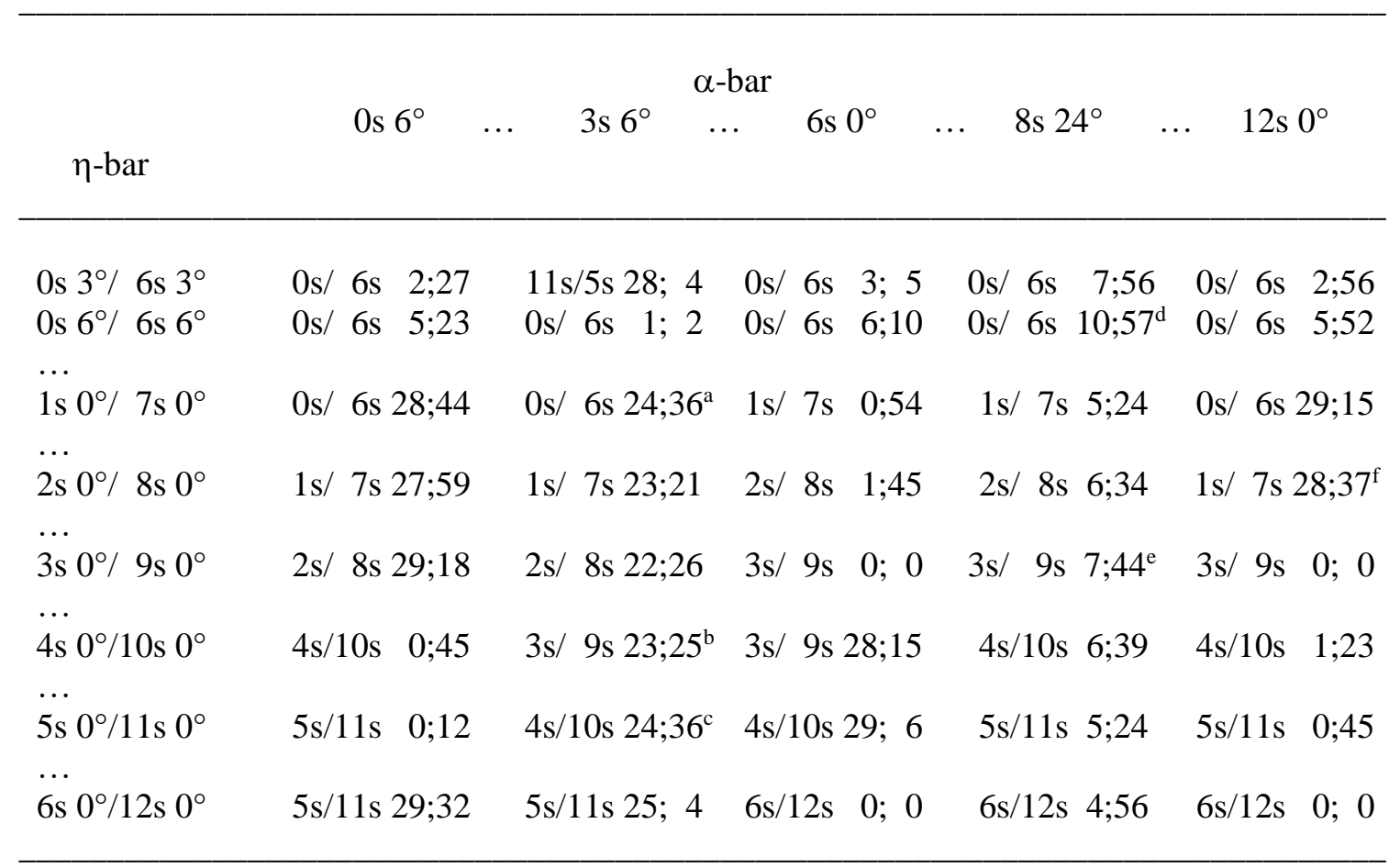
a. Mh and Oh: 24;33.
b. Vl: $23 ; 27$.
c. Vl: $24 ; 46$.
d. Vl: $10 ; 59$.
e. Vl: $7 ; 43$.
f. Vl and Mh: 28;38.

6. True longitude of the planets: Saturn (Cl, 126-137; Vl, 54v, Mh, 120b-126a; Oh, 71b-77b), Jupiter (Cl, 138-149; Mh, 126b-132a; Oh, 78a-84a), Mars (Cl, 150-165; Mh, 132b-140a; Oh, 69a71a, 84b-86b, 95b-98a), Venus (Cl, 166-179; Vl, 74v-81r; Mh, 140b-147a; Oh, 87a, 93b-95a, 98b-102b), and Mercury (Cl, 180-191; Vl, 81v-87r; Mh, 147b-153a; Oh, 87b-93a).

For each planet we are given a double argument table, where the argument at the head of the table is its mean anomaly, $\alpha$-bar, at intervals of $6^{\circ}$, and the argument at the left side (right side in Hebrew) of the table is its mean center, $\kappa$-bar, also at intervals of $6^{\circ}$. The entries represent the true longitude of the planet, in signs, degrees, and minutes: see Table 7 for the case of Venus and Figure 1 for the case of Mercury. These five tables agree, but for copyist's errors, with those in the Oxford Tables. They were analyzed by North (1977), who established the dependence of the Oxford Tables on the Tabule magne compiled by John of Lignères.

Table 7: True longitude of Venus (excerpt). ${ }^{15}$

\footnotetext{
${ }^{15}$ In this table mean anomaly is given at intervals of $6^{\circ}$, except for mean anomaly from $5 \mathrm{~s} 0^{\circ}$ to $7 \mathrm{~s} 0^{\circ}$, where the intervals are $3^{\circ}$. In Oh the transitions from one zodiacal sign to the next in columns (after the first column) are not marked, and so the user of this copy might associate the entry with the wrong sign. And on some pages in Oh the zodiacal signs are missing entirely.
} 


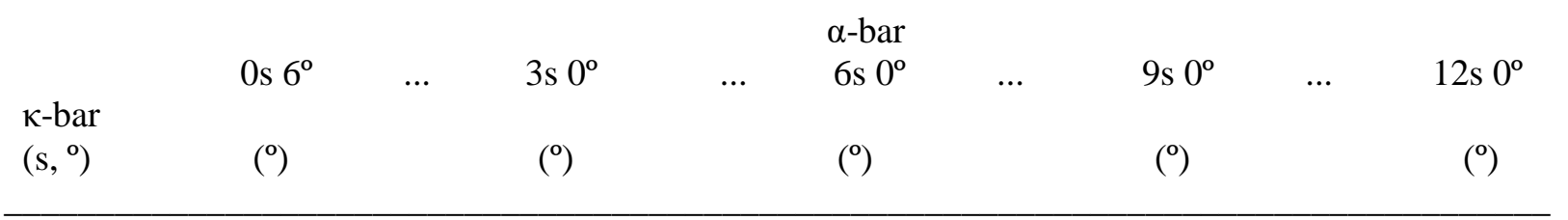

\begin{tabular}{rrrrrrrrrrrrrrrrr}
0 & 6 & Cnc & $8 ; 4$ & $\ldots$ & Leo & $10 ; 49$ & $\ldots$ & Cnc & $4 ; 58^{\mathrm{f}}$ & $\ldots$ & Gem & $0 ; 17$ & $\ldots$ & Cnc & $5 ; 34$ \\
0 & 12 & Cnc & $13 ; 56^{\mathrm{a}}$ & $\ldots$ & Leo & $16 ; 41$ & $\ldots$ & Cnc & $10 ; 14$ & $\ldots$ & Gem & $6 ;$ & 9 & $\ldots$ & Cnc $11 ; 26$ \\
$\ldots$ & & & & & & & & & & & & & & \\
3 & 0 & Lib & $0 ; 57$ & $\ldots$ & Sco & $3 ; 58^{\mathrm{e}}$ & $\ldots$ & Vir & $21 ; 58^{\mathrm{g}}$ & $\ldots$ & Leo & $22 ; 32$ & $\ldots$ & Vir $28 ; 27$ \\
$\ldots$ & & & & & & & & & & & & & & \\
6 & 0 & Cap & $2 ; 15$ & $\ldots$ & Aqr & $6 ; 0$ & $\ldots$ & Sgr & $29 ; 42$ & $\ldots$ & Sco & $23 ; 24$ & $\ldots$ & Sgr $29 ; 42$ \\
$\ldots$ & & & & & & & & & & & & & & \\
9 & 0 & Ari & $3 ; 29^{\mathrm{b}}$ & $\ldots$ & Tau & $6 ; 52$ & $\ldots$ & Ari & $7 ; 25$ & $\ldots$ & Aqr & $25 ; 26$ & $\ldots$ & Ari & $0 ; 57^{\mathrm{i}}$ \\
$\ldots$ & & & & & & & & & & & & & & \\
11 & 24 & Gem & $26 ; 20^{\mathrm{c}}$ & $\ldots$ & Cnc & $29 ; 7$ & $\ldots$ & Gem & $24 ; 21$ & $\ldots$ & Tau & $18 ; 35$ & $\ldots$ & Gem $23 ; 50$ \\
12 & 0 & Cnc & $2 ; 12^{\text {d }}$ & $\ldots$ & Leo & $4 ; 57$ & $\ldots$ & Gem & $29 ; 42$ & $\ldots$ & Tau & $24 ; 27^{\mathrm{h}}$ & $\ldots$ & Gem $29 ; 42$ \\
\hline
\end{tabular}
a. Oh: $13 ; 16$.
b. Vl: $3 ; 13$.
c. Vl: $25 ; 29$.
d. Vl: $2 ; 43$.
e. Vl: $4 ; 58$.
f. Vl: $4 ; 57$.
g. Oh: $22 ; 32$.
h. Oh: $20 ; 27$.
i. Oh: 0;27.

$<<$ Insert Figure 1 about here. $>>$

$<<$ Caption >> Figure 1. The first page of the table for the longitude of Mercury in the Tabule Parisiensis: Vatican, Biblioteca Apostolica, MS Pal. lat. 1436, 81v, where the zigzag line indicates the limit of each zodiacal sign. Note that the first zodiacal sign in the column between the argument and the entries is Scorpio. 


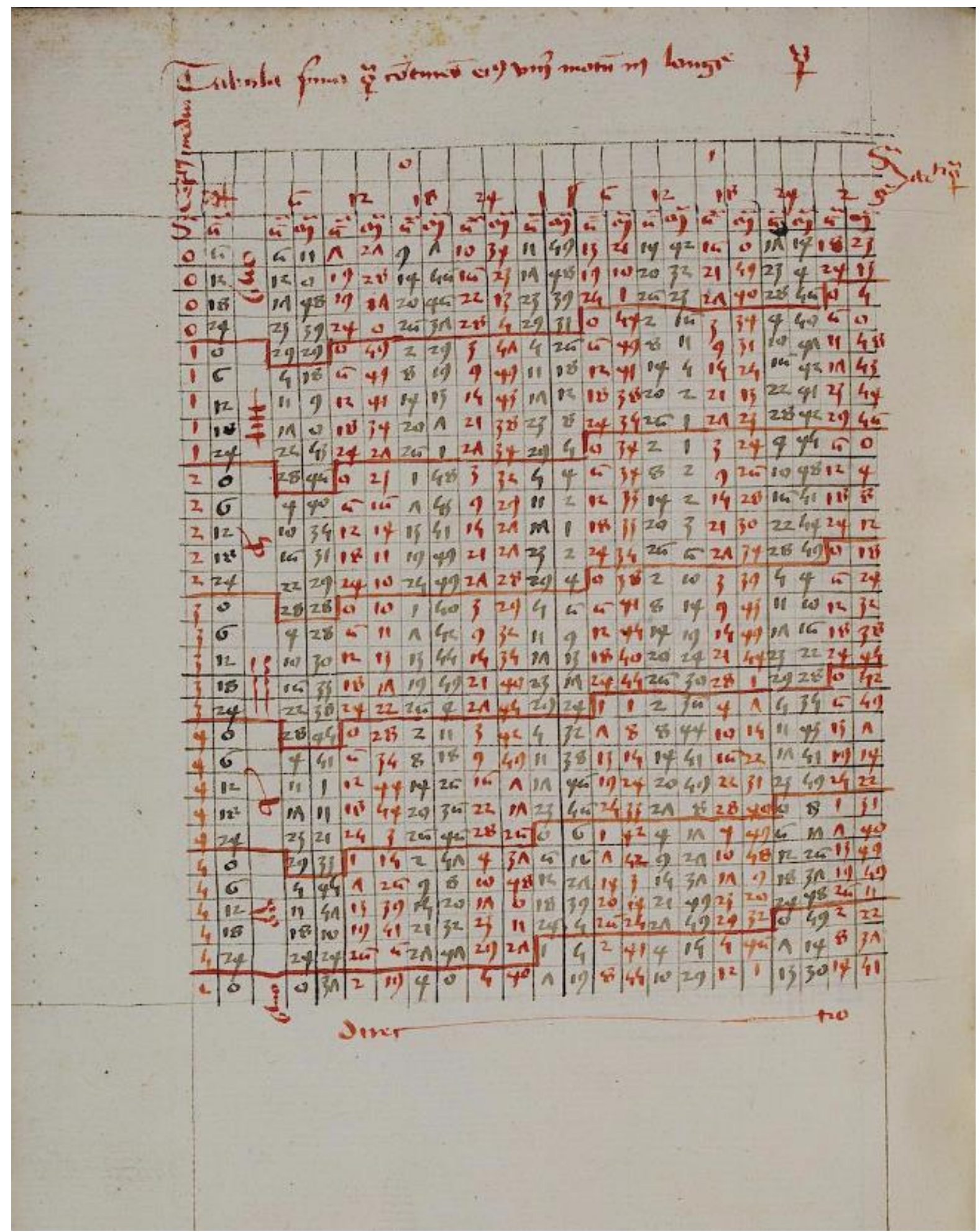


7. Planetary latitudes: Saturn (Mh, 154b-156a; Ph, 35b-37a), Jupiter (Mh, 156b-158a; Ph, 37b-39a), Mars (Mh, 158b-161a; Ph, 39b-42a), Venus (Mh, 161b-164a; Ph, 42b-45a), and Mercury (Mh, 164b-166a; Ph, 45b-48a).

As was the case with the tables for the longitude of the Sun, the Moon, and the five planets, these double argument tables for the latitudes of the planets are valid for any geographical position of the observer and for any time. There is a double argument table for each planet, and both arguments agree with those used in the table for planetary longitudes. The argument at the head of the table is its mean anomaly, $\alpha$-bar, at intervals of $15^{\circ}$, and the argument at the left side (right side in Hebrew) is its mean center, $\kappa$-bar, at intervals of $6^{\circ}$. The entries are given in degrees, and minutes, with an indication whether the latitude is North or South: see Table 8 for the case of Saturn. The five tables agree, but for copyist's errors, with those in the Oxford Tables.

Table 8: Latitude of Saturn (excerpt)

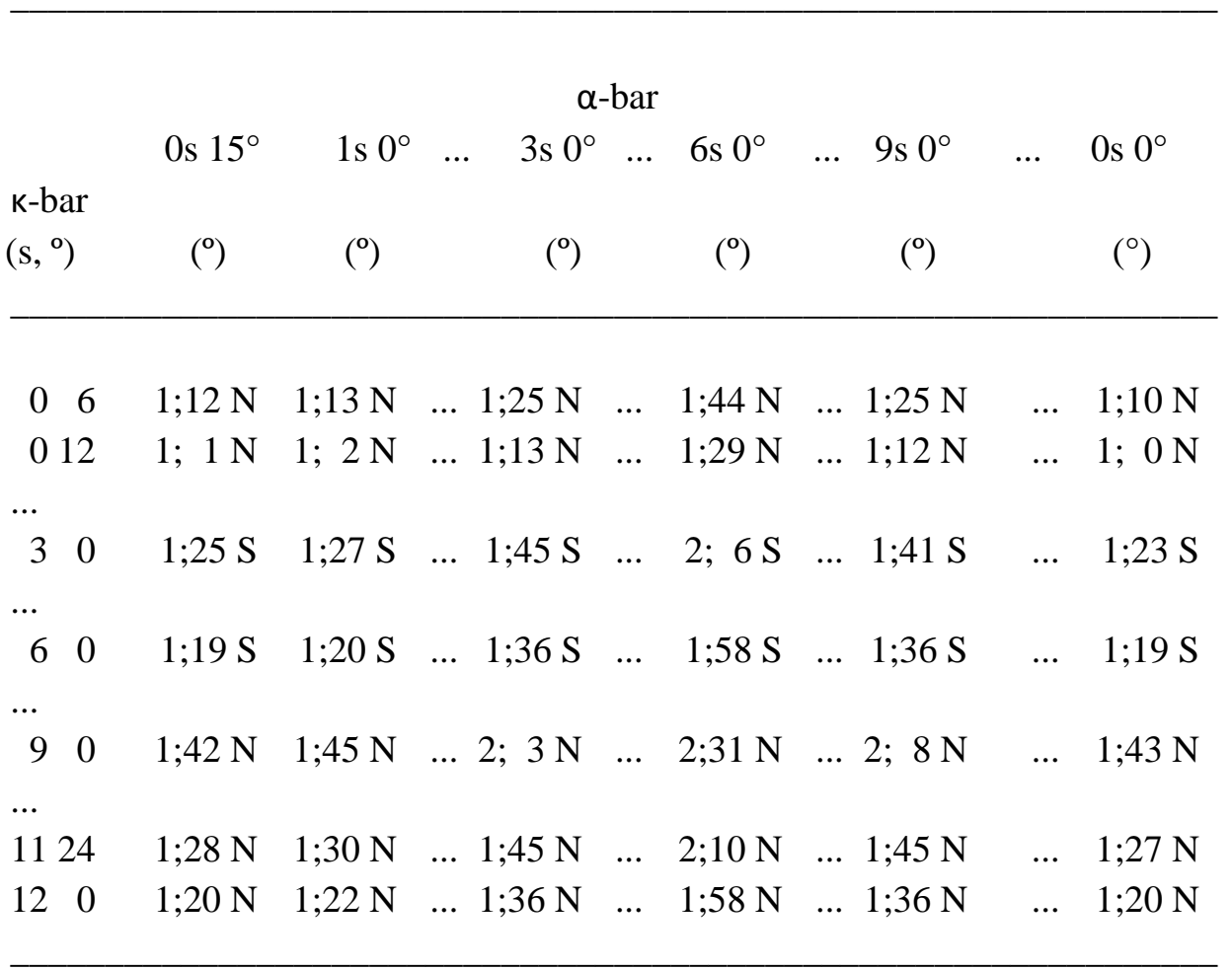

$\mathrm{N}=$ North; $\mathrm{S}=$ South

\section{The Oxford Tables in Mantua}

Mordecai Finzi (fl. 1440-1475) was responsible for another version of the Oxford Tables in Hebrew, with radices for noon, Dec. 31, 1443, Mantua, Italy, uniquely preserved in Oxford, Bodleian Library, MS Lyell 96, 3b-8a (canons), 8b-11a (radices), 12b-74b (tables), henceforth MS Lh. ${ }^{16}$ Finzi was familiar with several sets of astronomical tables in Hebrew and translated some Latin texts on

\footnotetext{
${ }^{16}$ Finzi's tables in MS Lh were first identified as a version of the Oxford Tables by B. R. Goldstein: see his "Descriptions of astronomical instruments in Hebrew", Annals of the New York Academy of Sciences, 500 (1987), pp. 105-141, on p.120.
} 
astronomy into Hebrew. On occasion he mentioned unnamed Christian collaborators. ${ }^{17}$ In particular, the colophon to Finzi's version of the Oxford Tables indicates that he completed the translation in Mantua in 1441 "with the help of a Christian" (MS Lh, 8a; cf. Langermann 1988, p. 26). Although the tables were translated from Latin, the canons were rearranged by Finzi. On f. 8b (margin), the coordinates of Mantua are given: longitude (from the West) $31 ; 45^{\circ}$, latitude $45 ; 10^{\circ}$. On f. 4a the longitude of Oxford (MS: in the city of Osonia in Anglia) is given as 17;56 from the western limit: this is consistent with the longitudinal distance from Oxford to Paris, given as $5 ; 4^{\circ}$ in the Oxford Tables, for the sum, $23 ; 0^{\circ}$ from the West, is the longitude of Paris (which also results from taking the longitude of Toledo to be $11^{\circ}$, and Paris to be $12^{\circ}(=0 ; 48 \mathrm{~h})$ from Toledo).

On f. 5b Finzi translated a marginal note in his archetype:

Know that from the time of the investigation [hitbonenut $]^{18}$ by Ptolemy to the time of the investigation by Alfonso the eighth sphere, as well as the fixed stars and the apogees, moved $17 ; 8^{\circ}$, and from the time of the investigation by Alfonso to 1360 of the Incarnation [it moved] $1 ; 9,8^{\circ} .{ }^{19}$ Hence, from the time of the investigation by Ptolemy to 1360 of the Incarnation the orb of the zodiac - that moves with its constellations - moved $18 ; 17,8^{\circ}$. At the time of Ptolemy's investigation, the [more] advanced star on the horn of Aries, which is the beginning of the constellation Aries, was distant from the beginning of the fixed orb of the zodiac $6 ; 40^{\circ} .{ }^{20} \mathrm{It}$ follows that at the end of year 1360 of the Incarnation it was distant from the fixed beginning of Aries $24 ; 57,8^{\circ}$.

According to Finzi, this passage was not part of the original canons to the tables of 1348; rather, it was a marginal gloss in the Latin copy on which he based his translation. In the canons to the Tabule Parisiensis there is a similar passage (see above): precession from the time of Ptolemy to that of Alfonso is $17 ; 8^{\circ}$ (as in Finzi) and, from the time of Alfonso to the end of 1368, 1;22,18,43 (which is not in Finzi).

A surprising feature of Finzi's version of the Oxford Tables is a table of oblique ascension for geographical latitude $51 ; 50^{\circ}$ ( $\mathrm{Lh}, 13 \mathrm{a}$ ) which, according to a copy of the Oxford Tables in Latin, is the latitude of Oxford (see Florence, Biblioteca Medicea Laurenziana, MS San Marco 185, 118r). Although we have not found this table for oblique ascension in the Latin copies of the Oxford Tables, it is included in the tables compiled by the Englishman William Rede (d. 1385), a set of astronomical tables derived from the Parisian Alfonsine Tables and adapted for the meridian of Oxford, with radices for 1340 (see, e.g., Oxford, Bodleian Library, MS Digby 97, 19v-20r). The canons to Rede's set explicitly state that the latitude of Oxford is $51 ; 50^{\circ}$. It would thus seem that Finzi's Latin copy of the Oxford Tables had a table of oblique ascension for the latitude of Oxford, computed by Rede or perhaps, by one of his colleagues at Merton College, Simon Bredon or John Ashenden. To be sure, a table for latitude $51 ; 50^{\circ}$ would be of no use for someone in Mantua whose latitude, according to Finzi, is $45 ; 10^{\circ}$, as noted above.

Of greatest interest in Finzi's tables for Mantua are the radices for Mantua and the computation of them that depend directly on the radices in the Oxford Tables for 1348 (Lh, 10b). In each case he begins with the radix for Mantua, noon, Dec. 31, 1348, that he seems to have computed

\footnotetext{
${ }^{17}$ See Y. T. Langermann, “The Scientific Writings of Mordekhai Finzi”, Italia, 7, 1988, pp. 8-11, 15-32. Reprinted in Y. T. Langermann, The Jews and the Sciences in the Middle Ages (Aldershot, 1999), Essay ix. ${ }^{18}$ In a parallel passage in the Hebrew version of the Tabule Parisiensis, the term is $h<.>$ aqira: Mh, $105 \mathrm{~b}$; Oh, 59a.

${ }^{19}$ Taking the time of Alfonso to be May 31, 1252, and 1360 to mean Dec. 31, 1360, we recompute the difference to be $1 ; 9,8^{\circ}\left(=18 ; 23,53^{\circ}-17 ; 14,45^{\circ}\right)$, in agreement with the text.

${ }^{20}$ See G. J. Toomer, Ptolemy's Almagest (New York, 1984), p. 360: $\gamma$ Ari.
} 
from the radices for Oxford (same date), by applying the distance between Mantua and Oxford: see Table 9, row 1 . The same radices as those in row 1 appear in a list on Lh, 17a, where the heading is on two lines: (1) Radices for the year 1348 according to the Christians; (2) Radices for the beginning of 1349 for the longitude of Mantua. Then in Lh, 10b, row 2, he introduces the motion in 95 years (= $1443-1348$ ), and in row 3 he gives the sum of the entries in the preceding two rows. Finally, he subtracts the motion of the eighth sphere and the results in row 4 are the radices for Mantua, noon, Dec. 31, 1343. We have compared Finzi's results with those based on the Parisian Alfonsine Tables for Toledo, Dec. 30, 1343, 22;37h after noon for, given the data cited by Finzi, the difference in longitude from Mantua to Toledo is $20 ; 45^{\circ}\left(=31 ; 45^{\circ}-11 ; 0^{\circ}\right)$, or $1 ; 23 \mathrm{~h}$. We also checked the entries in row 1, where the time difference between Mantua and Oxford is about $0 ; 55 \mathrm{~h}=1 ; 23 \mathrm{~h}$ (MantuaToledo) - 0;48h (Toledo - Paris) + 0;20,16h (Paris - Oxford). Among the motions tabulated, those in lunar elongation from the Sun and lunar anomaly are the swiftest; hence they are most affected by this time difference. The radix in the Oxford Tables for Dec. 31, 1348 for the lunar elongation is $4 \mathrm{~s}$ $4 ; 27,13^{\circ}$, and the motion in elongation in $0 ; 55 \mathrm{~h}$ is $0 ; 27,56^{\circ}\left[=\left(12 ; 11,27^{\circ} \cdot 0 ; 55\right) / 24\right]$; the difference is $4 \mathrm{~s} 3 ; 59,17^{\circ}$ [text: $4 \mathrm{~s} 4 ; 0,8^{\circ}$ ]. The radix in the Oxford Table for Dec. 31, 1348 for lunar anomaly is $11 \mathrm{~s} 27 ; 18,0^{\circ}$, and the motion in anomaly in $0 ; 55 \mathrm{~h}$ is $0 ; 29,56^{\circ}$ [ $\left.=(13 ; 3,54 \cdot 0 ; 55) / 24\right]$; the difference is $11 \mathrm{~s} 26 ; 48,4^{\circ}$ [text: $11 \mathrm{~s} 26 ; 48,8^{\circ}$ ]. The agreement is acceptable for the lunar elongation and very close for lunar anomaly. For the planets the recomputed values of the radices for Dec. 31,1443, noon, Mantua, are very close to the text, with the exception of Jupiter, where the difference is $-0 ; 16,57^{\circ}(=$ 8 s $20 ; 19,38^{\circ}-8$ s $20 ; 36,35^{\circ}$ ). This difference is due to the radix for 1348 , where Finzi agrees closely with the entry in the Oxford Tables (Finzi: 8 s $16 ; 56,0^{\circ}$ vs. $8 \mathrm{~s} 16 ; 56,8^{\circ}$ ). However, the value computed for the center of Jupiter with PAT for Dec. 31,1348 is 8 s $17 ; 13,14^{\circ}$ (Finzi - PAT $=-$ $\left.0 ; 17,14^{\circ}\right)$. With this correction, the difference in the center of Jupiter for Dec. 31, 1443, Mantua, is less than $0 ; 1^{\circ}$. Here is additional proof that Finzi depended on the Oxford Tables rather than directly on the Parisian Alfonsine Tables.

Table 9. Finzi, radices for Dec. 31, 1443, noon, Mantua (= Dec. 30, 1443, 22;37h after noon, Toledo); recomputations according to the Parisian Alfonsine Tables [PAT] are displayed in brackets

Table 9a.

(1) Their radices

(2) Their motion in 95 years

(3) Sum

[PAT

(4) We subtract from this anomaly the motion of the [eighth] sphere to obtain the appropriate solar anomaly [1] [PAT

$\begin{array}{rrrl}\text { solar anom. } & \text { lunar elong. } & \text { lunar anom. } & \text { asc. node } \\ \text { 6s } 18 ; 30,4^{\circ} & \text { 4s } 4 ; 0,8^{\circ} & 11 \text { s } 26 ; 48,8^{\circ} & \text { 3s } 25 ; 40,18^{\circ} \\ & & & \\ 11 \text { s } 29 ; 57,32 & 11 \text { s } 24 ; 35,4 & \text { 2s } 28 ; 59,0 & \text { 1s } 7 ; 25,0 \\ 6 \text { s } 18 ; 27,36 & 3 \text { s } 28 ; 35,12 & \text { 2s } 25 ; 47,8 & \text { 2s } 18 ; 15,18^{*} \\ & \text { 3s } 28 ; 34,8 & \text { 2s } 25 ; 44,24 & \text { 2s } 18 ; 15,46]\end{array}$

6s $17 ; 30,35$

6s $17 ; 30,29^{\circ}$ ] 
* Finzi adds: We subtracted the motion of the ascending node from its radix to obtain its true position.

Table $9 b$.

(1) Their radices center of Saturn center of Jupiter center of Mars

(2) Their motion $3 \mathrm{~s} 24 ; 46,10^{\circ} \quad 8 \mathrm{~s} 16 ; 56,0^{\circ}$ 5 s $26 ; 25,15^{\circ}$ in 95 years

2s $22 ; 16,12$

0s $4 ; 20,39$

6s $4 ; 6,31$

(3) Sum 6s $17 ; 2,22$ 8s $21 ; 16,39$

0s $0 ; 31,46$

(4) Subtract from them the motion of the [eighth] sphere [1]

Table 9c.
anom. Venus
anom. Mercury
center of Mercury
(1) Their radices
6s $15 ; 11,58^{\circ} \quad 0$ s $11 ; 55,25^{\circ}$
obtained when we subtract its combined difference from the solar anomaly
(2) Their motion in 95 years
5s $1 ; 53,0$
5s $6 ; 22,0$
(3) Sum
$11 \mathrm{~s} 17 ; 4,58$
5 s $18 ; 17,25$
2s $18 ; 16,25$
[PAT
$11 \mathrm{~s} 17 ; 2,7^{\circ} \quad 5 \mathrm{~s} 18 ; 14,12^{\circ}$
2s $\left.18 ; 16,19^{\circ}\right]$

\section{Comment.}
[1] The amount subtracted is $0 ; 57,1^{\circ}$.
The entries in the version of the Oxford Tables in MS Lh agree with those in the Latin version, but for minor variants: daily position of the Sun (Lh, 17b-18a), elongation of the Moon from the Sun (Lh, 18b-25a), Saturn (Lh, 25b-31a), Jupiter (Lh, 31b-34a), Mars (Lh, 34b-45a), Venus (Lh, 45b-52a), Mercury (Lh, 52b-58a; 58b-59a are blank), latitude of Saturn (Lh, 59b-62a), latitude of Jupiter (Lh, 62b-65a), latitude of Mars (Lh, 65b-68a), latitude of Venus (Lh, 68b-71a), and latitude of Mercury (Lh, 71b-74a). On Lh, 9b, and again on 17a, Finzi lists the planetary apogees, and they all agree exactly with the planetary apogees in the Oxford Tables: see Table 3, column 4.

\section{The Oxford Tables in Louvain}

About a century later, the instrument-maker and printer Henri Baers or Vekenstyl published in Louvain a set of tables under the title Tabule perpetue longitudinum ac latitudinum noviter copulate ad meridiem alme universitatis Lovanienses (1528). ${ }^{21}$ After a short text explaining the use of the tables and displaying several worked examples for 1520, we find tables for the equation of time, animodar, mean motions and equations of the celestial bodies, latitude of the Moon and the five planets, proportions, geographical coordinates, and equation of the houses for geographical latitude

\footnotetext{
${ }^{21}$ For a facsimile of the Tabule perpetue, together with a French translation and commentary, see E. Poulle and A. De Smet, Les tables astronomiques de Louvain de 1528 (Brussels, 1976).
} 
$51^{\circ}$. All tables use signs of 30 degrees, as is the case of many sets in the Alfonsine tradition, including the Oxford Tables.

The table for animodar $\left(\mathrm{B} . \mathrm{i}^{\mathrm{v}}-\mathrm{B} . \mathrm{ii}^{\mathrm{v}}\right)$ gives the time from conception to birth in weeks, days, hours, and minutes. This table is the same as that found in Abraham Zacut's Almanach perpetuum published in Leiria, Portugal, in 1496 and later reprinted in 1502 and $1525 .{ }^{22}$ Moreover, the chapter on nativities in Baers' canons was taken almost word-by-word from the corresponding canons in the Latin version of the Almanach perpetuum.

In the Tabule perpetue for Louvain, the mean motion tables give radices for 1520, 1540, and 1560 , collected years in periods of 20 years, and then in single years from 1 to 20 , as is the case in several previous sets of tables, including the Oxford Tables.

The tables for planetary latitudes are presented as five double argument tables, one for each planet, with mean anomaly, $\alpha$-bar, at the head of the table and mean center, $\kappa$-bar, at the left of the table. The entries, the format, and the intervals of the two arguments agree with those in the corresponding tables in the Oxford Tables. However, the presentation is slightly different because, for the superior planets, Baers shifted the rows in order to present southern and northern latitudes on separate pages. So, the table for the latitude of Saturn begins at $\kappa$-bar $=1 \mathrm{~s} 18^{\circ}$ (the text erroneously gives $1 \mathrm{~s} 12^{\circ}$ ), that for Jupiter at $\kappa-b a r=4 \mathrm{~s} 0^{\circ}$, and that for Mars at $\kappa-b a r=3 \mathrm{~s} 12^{\circ}$. In all three cases the first column is for $\alpha$-bar $=0 \mathrm{~s} 15^{\circ}$. We note that in the case of Saturn, the table is especially flawed, for several rows are missing and others do not have the proper entries. For Venus and Mercury, this typographical solution was no longer possible and, instead of using a zigzag dividing line between northern and southern latitudes as in the manuscript copies, it was decided to print the latitude tables of the inferior planets in two colors, black and red, with an explanation below the table indicating that the color used for southern latitudes is black and that for northern latitudes is red.

The Tabule perpetue for Louvain do not mention the Tables of Oxford or Zacut's tables, from which they were derived. It is of interest that this was the first publication of the Tables of Oxford, at least partially, almost two centuries after their compilation.

\section{Acknowledgements}

We are grateful to Gad Freudenthal and Y. Tzvi Langermann for their help with Hebrew terminology, to Ofer Elior who provided valuable assistance in obtaining an electronic copy of Finzi's tables (MS Lh), and to the anonymous referee for his/her comments.

\section{Notes on contributors}

José Chabás, Emeritus Professor at the Universitat Pompeu Fabra, Barcelona, has written extensively on history of astronomy in the Middle Ages and Early Modern Period and is currently working on a survey of sets of astronomical tables in Latin in that period.

Bernard R. Goldstein, University Professor Emeritus, Dietrich School of Arts and Sciences, University of Pittsburgh, has collaborated with José Chabás for many years; our most recent coauthored book is Essays on Medieval Computational Astronomy (Leiden and Boston, 2015).

\footnotetext{
${ }^{22}$ See J. Chabás and B. R. Goldstein, Astronomy in the Iberian Peninsula: Abraham Zacut and the Transition from Manuscript to Print. Transactions of the American Philosophical Society, 90, Part 2. (Philadelphia, 2000), pp. $86,150-153$.
} 